\title{
Arbovirus (dengue type) as a cause of acute myocarditis and pericarditis
}

\author{
N. Nagaratnam, K. Siripala, and Nandani de Silva \\ From the Government Hospital, Gampaha, W.P. Sri Lanka
}

Two cases of myocarditis believed to be due to arbovirus (dengue type) are reported. One other had evidence of arbovirus infection which may have had no relation to the cardiac involvement. Two of them had pericarditis as well. The serological findings and the importance of recognition of this potential cause of myocarditis are discussed.

The arbovirus (arthropod-borne) comprises a large group, now numbering more than 200 types, of which at least 50 have been associated with disease in man. The best known ones are found in Group A and Group B. They commonly manifest with fever, headache, general and local pain, and less commonly rash and lymphadenopathy. Many virus illnesses have been associated with myocarditis and pericarditis and it is only recently that a large number of potential causes of myocarditis have been appreciated.

We wish to report a case of myocarditis with pericarditis caused by dengue virus. Two others are briefly mentioned for one has already been the subject of another communication (Nagaratnam and de Silva, 1972).

\section{Case I}

\section{Case reports}

A woman aged 32 years was admitted in January 1972 with left-sided chest pain, palpitations, and breathlessness of sudden onset of a few hours' duration. She had been having fever with generalized aches and pains from the previous day. There were no past illnesses of note.

Examination revealed a woman of small build who was breathless at rest. Her pulse was 160 a minute, regular and of small volume. Apart from the tachycardia there was no abnormality in the heart. The lungs were clear and neither the liver nor spleen was palpable.

An electrocardiogram revealed sinus rhythm with a heart rate of 144 a minute. The complexes were of low voltage. She was confined to bed and sedated. That noon she had fever and she continued to have fever daily in the evenings, accompanied by sweats. She continued to be breathless and complained of a pain in the right side of her chest. Radiological examination revealed

Received 22 June 1972. a shadow in the right base. White blood cells $13,000 /$ $\mathrm{mm}^{3}$, neutrophils 70 per cent, lymphocytes 24 per cent, and eosinophils 6 per cent. Erythrocyte sedimentation rate $35 \mathrm{~mm}$. A repeat electrocardiogram on the same day showed a rate of 144 a minute with inverted and flattened $T$ waves in most leads.

She was treated with penicillin at this stage. A pericardial rub and a pleural rub were heard two days later and a grade $2 / 6$ systolic murmur at the apex. There was diminished air entry at the base of the right lung. Two days later she had signs of an effusion. Radiological examination showed shadowing in both lung bases and mid-zones with an effusion on the right side. Twelve days after being admitted pleural aspiration was done and $200 \mathrm{ml}$ straw-coloured fluid was withdrawn. Culture of the fluid revealed no organisms. White blood cells II $400 / \mathrm{mm}^{3}$, neutrophils 60 per cent, lymphocytes 35 per cent, eosinophils 2 per cent, and monocytes 3 per cent.

After aspiration the temperature rose and kept at a higher level than previously. She was then treated with ampicillin and cloxacillin. A second aspiration was done early in February and on this occasion pus was withdrawn. It was thought that the pleural cavity had been infected as a result of the first aspiration. Culture again revealed no growth. Erythrocyte sedimentation rate II2 $\mathrm{mm}$.

Three days later another $200 \mathrm{ml}$ pus was aspirated. Radiological examination revealed a decrease in the amount of fluid within the pleural cavity. As the fever continued in spite of the antibiotics, she was given prednisolone ( $40 \mathrm{mg}$ daily). On the following day her fever settled and continued to remain so. Her general condidition improved and she was sent home in the middle of February, about a month after being admitted. Her $x$-ray at the time of discharge from hospital revealed a small effusion in the right base. There was no cardiac enlargement. Electrocardiogram showed the same changes, but the $T$ wave inversions were less deep. Haemagglutination test for toxoplasmosis negative; SGOT 90 (23-IIO) units, SGPT 60 (20-I IO) units, LE 
TABLE I Electrocardiographic and radiological findings

\begin{tabular}{|c|c|c|c|c|c|c|}
\hline \multirow{2}{*}{$\begin{array}{l}\text { Case } \\
\text { No. }\end{array}$} & \multirow[t]{2}{*}{ Electrocardiographic findings } & \multicolumn{3}{|c|}{ Radiological findings } & \multicolumn{2}{|l|}{ Lungs } \\
\hline & & Heart size & No change & $\begin{array}{l}\text { Progressive } \\
\text { enlargement }\end{array}$ & Effusion & Congestion \\
\hline I & $\begin{array}{l}\text { Tachycardia, sinus rhythm, low voltage, flat } \\
\text { and inverted } \mathrm{T} \text { waves } \\
\text { Tachycardia, atrial fibrillation, low voltage, }\end{array}$ & Normal & + & 0 & + & + \\
\hline 3 & $\begin{array}{l}\text { nonspecific } T \text { wave changes } \\
\text { Tachycardia, atrial fibrillation, low voltage, }\end{array}$ & Enlarged & - & + & + & + \\
\hline & nonspecific $T$ wave changes & Enlarged & - & + & 0 & + \\
\hline
\end{tabular}

cell phenomenon negative. The results of the serological tests for arbovirus are shown in Table 2.

\section{Case 2}

This 25-year-old man was first admitted with fever, headache, and vomiting. He was sweating, and the pulse was I20 a minute, irregular and of small volume. Blood pressure $90 / 60 \mathrm{mmHg}$.

Since then he had been admitted on several occasions with pain in chest, breathlessness, and swelling of the legs. There was progressive enlargement of the heart, with a right-sided pleural effusion and a third heart sound. Electrocardiogram showed atrial fibrillation with nonspecific $\mathrm{T}$ wave changes. His last admission was in March 1971, 7 months after the onset of his illness. Results of the radiological, electrocardiographic, and serological tests are shown in Tables $I$ and 2, respectively.

\section{Case 3}

A 22-year-old man was admitted with breathlessness and cough of about 3 months' duration. He had fever at the onset of his illness. Examination revealed a rapid irregular pulse, cardiac enlargement, and a pericardial rub. Results of the radiological, electrocardiographic, and serological tests are shown in Tables I and 2.

\section{Serological studies}

The serological tests were the haemagglutinationinhibition for Group B and Group A arbovirus. The sera were examined at various stages of their illnesses and the results are shown in Table 2. A diagnosis of group B arbovirus is very likely in Case $I$, presumptive in Case 2, and in Case 3 the arbovirus infection may have occurred 12 and 14 weeks earlier or even 1 or 2 years earlier, and may have had no relation at all to the carditis; it is possible therefore that there was another cause for the cardiomegaly in this case.

\section{Discussion}

There are several causes of myocarditis, including bacteria, rickettsiae, fungi, parasites, viruses, and toxic agents. Several reviews on the clinical aspects of myocarditis and pericarditis have been published. Suggestive symptoms, as in Case I, include a recent respiratory infection followed by pleural or pericardial pain, breathlessness, and palpitations. On examination there is severe tachycardia at rest and irregular heart beats. A third heart sound is often heard. $X$-ray may show cardiac enlargement and electrocardiogram T and RT wave changes. Pericarditis rarely occurs without clinical or histological

TABLE 2 Serological studies

\begin{tabular}{|c|c|c|c|c|c|c|}
\hline \multirow{2}{*}{$\begin{array}{l}\text { Case } \\
\text { No. }\end{array}$} & \multicolumn{5}{|l|}{ Group $B$} & \multirow{2}{*}{$\frac{\text { Group } A}{\text { Comment }}$} \\
\hline & $\begin{array}{l}\text { Time of } \\
\text { illness }\end{array}$ & Dengue $I$ & Dengue II & $\begin{array}{l}\text { Fapanese } \\
\text { encephalitis }\end{array}$ & Chikungunya & \\
\hline I & $\begin{array}{l}\text { 8th dy } \\
\text { 7th wk }\end{array}$ & $\begin{array}{r}>2560 \\
640\end{array}$ & $\begin{array}{r}>2560 \\
320\end{array}$ & $\begin{array}{r}>2560 \\
160\end{array}$ & $\begin{array}{l}<20 \\
<20\end{array}$ & Suggestive of recurrence of Group B infection \\
\hline 2 & 3 rst dy & 640 & 320 & $>1280$ & $>80$ & Group B antibody present in significant titre \\
\hline 3 & I th wk & 160 & 160 & $\begin{array}{r}80 \\
60\end{array}$ & $\begin{array}{l}<20 \\
<20\end{array}$ & Group B antibody present \\
\hline & I4th wk & 160 & 160 & 160 & $<20$ & \\
\hline
\end{tabular}


evidence of myocarditis though the reverse is not necessarily true (Pankey, 1965). Cases I and 3 in this study had clinical evidence of pericardial involvement.

Laboratory diagnosis is based on culture and isolation of the virus from the pericardial fluid or biopsy material and from changing antibody titres to a specific virus. In a particular virus infection, a purely serological diagnosis can only be made in a current infection when 2 samples show a fourfold rise or fall in titre. When a single specimen shows a titre above that found in the 'normal' person, a presumptive diagnosis may be made.

Dengue illness caused by Group B viruses is endemic in Ceylon. In a study of arbovirus infection in Ceylon, Vesenjak-Hirjan, Hermon, and Vitarana (1969) found that the percentage of positive reactors to Group B viruses ranged from 16.3 to 84.6 per cent. When they compared the antibody titres of the indigenous population with those of a group of immigrant Yugoslav workers they found that a titre of $I: 640$ would represent a significant titre for a recent infection. Little is known about the effect of dengue virus on the heart and in a patient with preexisting heart disease. Group A arbovirus has been associated with electrocardiographic changes though no clinical involvement of the heart had been seen in one series (Thiruvengadam, Kalyanasunderam, and Rajgopal, 1965). Bradycardia and hypotension were notable features. Weinbren, Haddow, and Williams (1958) had noted foci of necrosis and a foamy appearance of the myocardium in mice infected with chikungunya virus.
Recognition of myocardial involvement is important, for subsequent prognosis may be related to the degree of myocardial damage at the time of the initial diagnosis (British Medical fournal, 1971). Secondly, there is strong evidence that a large number of cases with obscure cardiomegaly are infective in origin when laboratory tests at that stage are not helpful in establishing the aetiology.

We wish to thank Drs. Y. Herman and U. T. Vitarana of the Department of Virology, Medical Research Institute, for the serological studies, and the Director of Health Services, Colombo, for permission to publish this paper.

\section{References}

British Medical fournal (197I). Annotation. Non-rheumatic myopericarditis. 2, 544 .

Nagaratnam, N., and de Silva, S. P. (1972). Myocarditis and infective cardiomyopathy in Ceylon. In the press.

Pankey, G. A. (1965). Effect of viruses on the cardiovascular system. American fournal of the Medical Sciences, 250, 103.

Thiruvengadam, K. V., Kalyanasunderam, V., and Rajgopal, J. (1965). Clinical and pathological studies on chikungunya fever in Madras City. Indian fournal of Medical Research, 53, 729.

Vesenjak-Hirjan, J., Hermon, Y., and Vitarana, T. (1969). Arbovirus infections in Ceylon. Bulletin of the World Health Organization, 4I, 243.

Weinbren, M. P., Haddow, A. J., and Williams, M. C. (1958). The occurrence of chikungunya virus in Uganda. Transactions of the Royal Society of Tropical Medicine and Hygiene, 52, 253 .

Requests for reprints to Dr. N. Nagaratnam, General Hospital, Colombo, Sri Lanka. 